\title{
Development of a solar intermittent refrigeration system for ice production
}

\author{
G. Moreno-Quintanar, W. Rivera*, R. Best \\ Centro de Investigación en Energía, Universidad Nacional Autónoma de México \\ A.P.34, 62580 Temixco, Mor., México \\ * Corresponding author: Tel. +52 5556229740,E-mail address: wrgf@cie.unam.mx
}

\begin{abstract}
A solar powered intermittent absorption refrigeration system has been developed at the Centro de Investigación en Energía of the Universidad Nacional Autónoma de México. The system was evaluated with the ammonia/lithium nitrate/water (NH3/LiNO3/H2O) mixture. The system was designed to produce up to $8 \mathrm{~kg} / \mathrm{day}$ of ice. The system consists of a Compound Parabolic Concentrator (CPC) with a cylindrical receiver acting as the generator/absorber, a condenser, an evaporator and an expansion valve. The system operates exclusively with solar energy and no moving parts are required. Evaporator temperatures as low as $-11^{\circ} \mathrm{C}$ were obtained for a period of time up to 8 hours. Coefficients of performance as high as 0.098 were obtained. These coefficients were $24 \%$ higher than those obtained with the same system operating with the binary ammonia/lithium nitrate (NH3/LiNO3) mixture previously reported in the literature. The results showed that the developed system seems to be a good alternative for refrigeration in zones where electricity is not available.
\end{abstract}

Keywords: solar cooling, absorption systems, ice production, ammonia/lithium nitrate/water.

\section{Nomenclature}

A concentrator aperture area

Cp heat capacity

$\mathrm{COP}_{S}$ solar coefficient of performance

$G \quad$ solar radiation ................................... $\mathrm{W} \mathrm{m}^{-2}$

$\mathrm{H} \quad$ insolation ...................................... $\mathrm{MJ} \mathrm{m}^{-2}$

$h_{\text {fus }} \quad$ heat of fusion of ice ...................... $\mathrm{kJ} \mathrm{kg}^{-1}$

$Q_{E V}$ cooling capacity MJ
$Q_{R}$ heat received from solar radiation..........MJ

$T$ temperature ............................................. K

$t \quad$ time .................................................... $s$

$\rho \quad$ density ........................................ $\mathrm{kg} \cdot \mathrm{m}^{-3}$

$v \quad$ specific volume …........................... $\mathrm{m}^{3} \mathrm{~kg}^{-1}$

m mass................................................. $\mathrm{kg}$

\section{Introduction}

Solar refrigeration is a useful application in areas of the world with high insolation levels where there is a demand for cooling and there is not electricity to supply conventional power systems.

Although the basic concepts of solar refrigeration appeared since about five decades, to date there are only a limited number of developed systems reported in the open literature, some of the most important works are the following. Erhard et al. [1] reported the performance of a solar refrigeration system operating with $\mathrm{NH}_{3} / \mathrm{SrCl}_{2}$. The main part of the device is an absorber/desorber unit which is mounted inside a concentrating solar collector in which the heat of absorption is transported out of the solar collector by means of two horizontally working heat pipes. The overall efficiency defined as the cooling capacity to the solar radiation received by the solar collectors of the cooling system varied from 0.05 to 0.08 . Wang et al. [2] published the results of a combined adsorption heating and cooling system which operated with activated carbon/methanol. The system was tested with electric heating and it was found that with $61 \mathrm{MJ}$ heating it was able produce up to $9 \mathrm{~kg}$ ice were made. The calculated Coefficient of Performance (COP) which is defined as the cooling capacity to the heat supplied to the generator of the system 
was 0.0591. Li et al. [3] published the experimental study on dynamic performance of a flat-plate solar solid-adsorption refrigeration for ice maker operating with activated carbon/methanol. The experimental results showed that this machine can produce 4-5 kg of ice after receiving 14-16 MJ of radiation energy with a surface area of $0.75 \mathrm{~m}^{2}$, while producing $7-10 \mathrm{~kg}$ of ice after receiving 28-30 MJ of radiation energy with $1.5 \mathrm{~m}^{2}$. Hildbrand et al. [4] reported the results of the performance of an adsorptive solar refrigerator built in Yverdon-les-Bains, Switzerland operating with the adsorption pair silicagel + water. Cylindrical tubes function as both the adsorber system and the solar collector. The condenser is air-cooled and the evaporator contains $40 \mathrm{l}$ of water that can freeze. The results showed that the gross solar coefficient of performance defined by the authors varied between 0.1 and 0.25 with a mean value of 0.16 . Khattab [5] presented the description an operation of a novel solar-powered adsorption refrigeration system operating with activated carbon/methanol. The system consisted of a modified glass tube having a generator (sorption bed) at one end and a combined evaporator and condenser at the other end and a simple arrangement of plane reflectors to heat the generator. The daily ice production was 6.9 and $9.4 \mathrm{~kg} / \mathrm{m}^{2}$ and the net solar COP was 0.136 and 0.159 for cold and hot climate respectively. Li et al. [6] developed a no valve, flat plate solar ice maker on the basis of previous research achievements. The system operated again with activated carbon/methanol. The authors reported that the no valve solar ice maker prototype was approached to practical application of mass production from view of cost and techniques. Rivera et al [7] published a paper about the development of a solar intermittent system operating with the ammonia/lithium nitrate mixture. The authors reported that solar coefficients of performance as high as 0.08 can be obtained whit the developed system

From the literature review it is clear that although has been relevant research on developing solar refrigeration systems the most of them have been focused in adsorption systems which have in general low coefficients of performance. Because of this in the present paper the system developed previously by Rivera [7] was evaluated but using now the ternary mixture ammonia/lithium nitrate/water with the purpose to increase the mixture conductivity and to decrease the mixture viscosity trying to increase the system efficiency. Physical and thermodynamic properties of the ternary mixture were taken from Libotean et al $[8,9]$.

\section{System description}

The system was designed to operate with the ammonia/lithium nitrate/water mixture for a maximum capacity of $8 \mathrm{~kg}$ of ice/day. It consists of a compound parabolic collector CPC with a cylindrical receiver acting as the generator/absorber, a condenser, a storage tank, an expansion valve, a capillary tube, an evaporator and a (see Fig. 1). The system operates exclusively with solar energy and no moving parts are required.

During the day, the ammonia/lithium nitrate/water mixture in the generator-absorber is heated by the solar radiation incident on the CPC until it reaches the saturation temperature. Then the ammonia is partially evaporated from the solution. Due to the increase of the temperature and consequently of the pressure of the solution in the cylindrical receiver of the CPC, the ammonia vapor goes to the condenser, where it is condensed by water and then it is stored in the tank. In the night, the temperature and pressure in the generator-absorber decreases because of the decreases of the ambient temperature and the ammonia liquid passes through the expansion valve (which is opened manually) decreasing its pressure and temperature, producing the refrigerant 
effect in the evaporator. After the ammonia has absorbed heat from the water stored in the trays inside the evaporator, the pressure in this component increases. In this way, the pressures are inverted in the components in natural way, and the ammonia vapor returns to the generatorabsorber where it is absorbed by the strong solution. About 7 o'clock in the morning, after the ice has been produced and the ammonia has been absorbed by the solution stayed in the cylindrical receiver of the CPC, the expansion valve is closed and the ice removed from the trays leaving the system ready for a new cycle.

The CPC is made out of an aluminum sheet with a reflectance of 0.85 . The cylindrical receptor is covered with a selective black paint with a range of emittance from 0.25 to 0.49 and absorptance from 0.88 to 0.94 ; it resists temperatures higher than $300^{\circ} \mathrm{C}$. The CPC's concentration ratio is 3.3, with a half-angle of $11.54^{\circ}$ and an aperture area of $2.54 \mathrm{~m}^{2}$. The condenser is a heat exchanger composed of a helicoidal aluminum coil, immersed in a water store. The water inside of the condenser is continuously recirculated by a pump that is connected to a cooling system. It is important to mention that the pump is used just in order to keep the condenser temperature fixed eliminating the system variability with regard to the ambient temperature, however, this pump it is not necessary in normal operating conditions. Furthermore the cooling system and the pump are used exclusively to control the temperature of cooling water for experimental purposes. The cylindrical storage tank has a capacity of $8.5 \mathrm{~L}$; a tube to measure the level is connected to the tank. Leaving the tank, there are two expansion devices: the capillary tube and the needle valve. Only one of these expansion devices is used during the evaporation process. The capillary tube is recommended because it permits the automation of the evaporation process. The evaporator is a heat exchanger that consists of a coil inside an insulated metal container with a front door, in which the ice is produced. The coil is horizontally distributed along five levels, each one bearing an aluminum tray. Water to be frozen is contained in these trays. Fig. 2 shows a photograph of the developed system.

In order to evaluate the system, 14 thermistors, 7 wall thermocouples, 5 pressure transducers, 2 manometers, 1 level tube (placed in the storage tank) and 1 pyranometer were used (see Fig. 1).

\section{Evaluation parameters}

Five main parameters were used in order to evaluate the experimental system: (i) the amount of the ammonia produced in the generator, (ii) the insolation, (iii) the solar energy received by the CPC, (iv) the cooling capacity and (v) the solar coefficient of performance.

The amount of the ammonia produced in the generator can be obtained as:

$$
m_{N_{3}}=\rho v_{N H_{3}}
$$




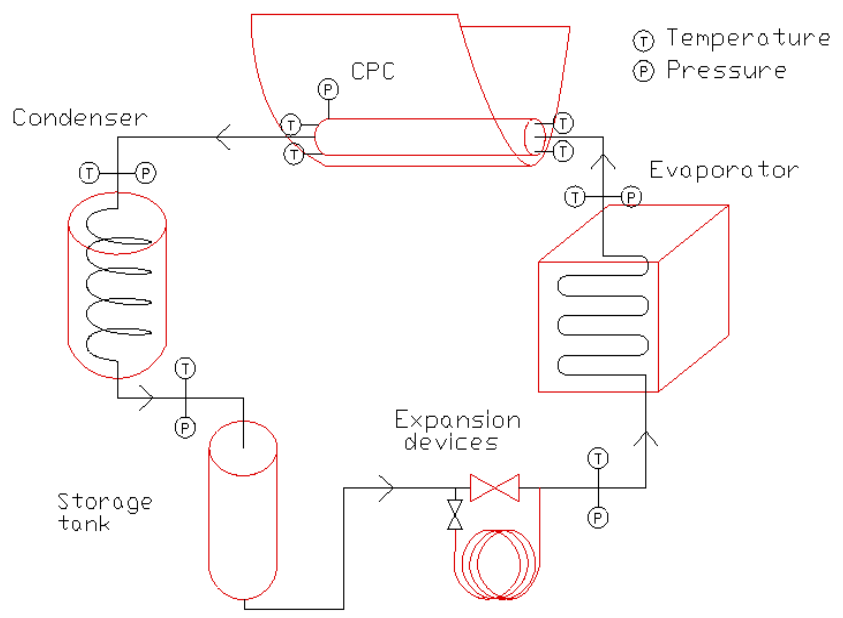

Fig. 1. Schematic diagram of the solar intermittent absorption refrigeration system.

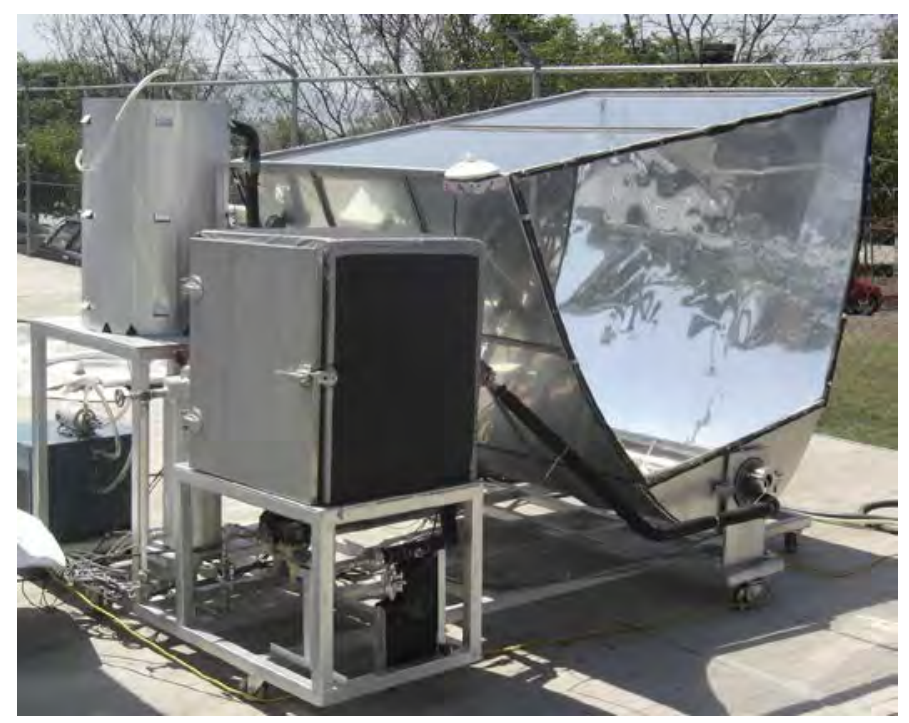

Fig. 2. Photograph of the solar intermittent absorption refrigeration system developed.

The energy received from the solar radiation is calculated as the sum of the contributions of the product of the irradiation, the time and the aperture area.

$$
Q_{R}=\sum_{i=1}^{n} G_{i} t A
$$

The cooling capacity is the sum of the sensible heat to reduce the water temperature from ambient to $0^{\circ} \mathrm{C}$ plus the heat of fusion of ice 


$$
Q_{E V}=m_{H_{2} O}\left(h_{f u s}+C_{p} \Delta T\right)
$$

Finally, the solar coefficient of performance is defined as the cooling capacity in the evaporator to the energy received from the solar radiation.

$$
\operatorname{COP}_{S}=\frac{Q_{E V}}{Q_{R}}
$$

\section{Results}

In order to experimentally evaluate the solar refrigeration system operating the two mixtures, more than 40 tests runs were carried out mainly during summer time, however, only 18 were taken in the analysis since in the others the solar radiation was considerably low (lower than 14MJ) because of long cloudy skies periods (normally higher than 2 hours).

During the experimental test runs, the main evaluating parameters such: temperatures, solar radiation and pressures were logged every 15 seconds.

Fig. 3 shows the maximum pressure reached in the cylindrical receiver against the maximum solution temperature reached during the generation stage. It can be observed that the pressure increases slightly win the increment of the solution temperature. The solution temperatures varied from $87^{\circ} \mathrm{C}$ to $112^{\circ} \mathrm{C}$, meanwhile the pressures varied from 13 bar to 16.1 bar.

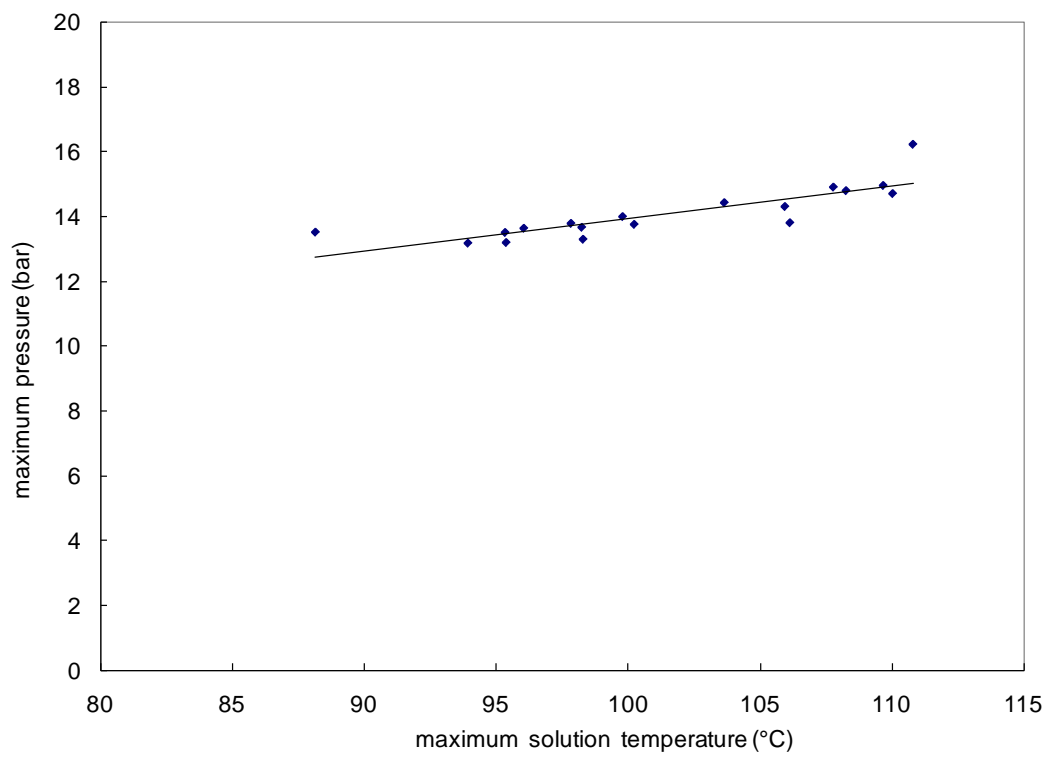

Fig. 3. Maximum pressure against maximum solution temperature for the solar system. 


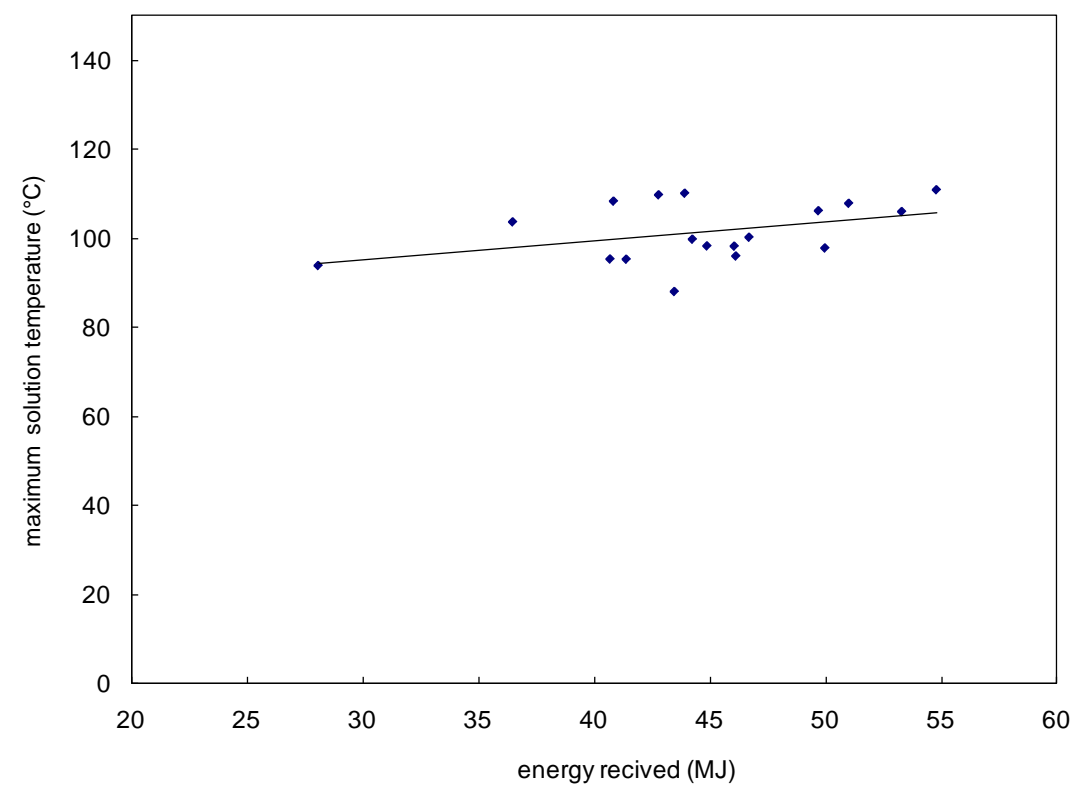

Fig. 4. Maximum solution temperature against the energy received by the CPC.

Fig. 4 shows the maximum temperature reached by the solution during the generation stage as function of the energy received by the CPC during the sunshine hours. In this figure it can be seen that there is a considerable data dispersion between these two parameters, however, it can be observed as it was expected that the solution temperature increases with the energy received by the CPC. It can be observed that the energy received by the CPC varied considerably from about $27 \mathrm{MJ}$ to $56 \mathrm{MJ}$ which is almost two times the minimum value. The high difference that exist among the energy received values is related with the cloudy of each day, since the solar radiation was almost the same since the most of the values (16 of the total) were obtained during the same season (summer).

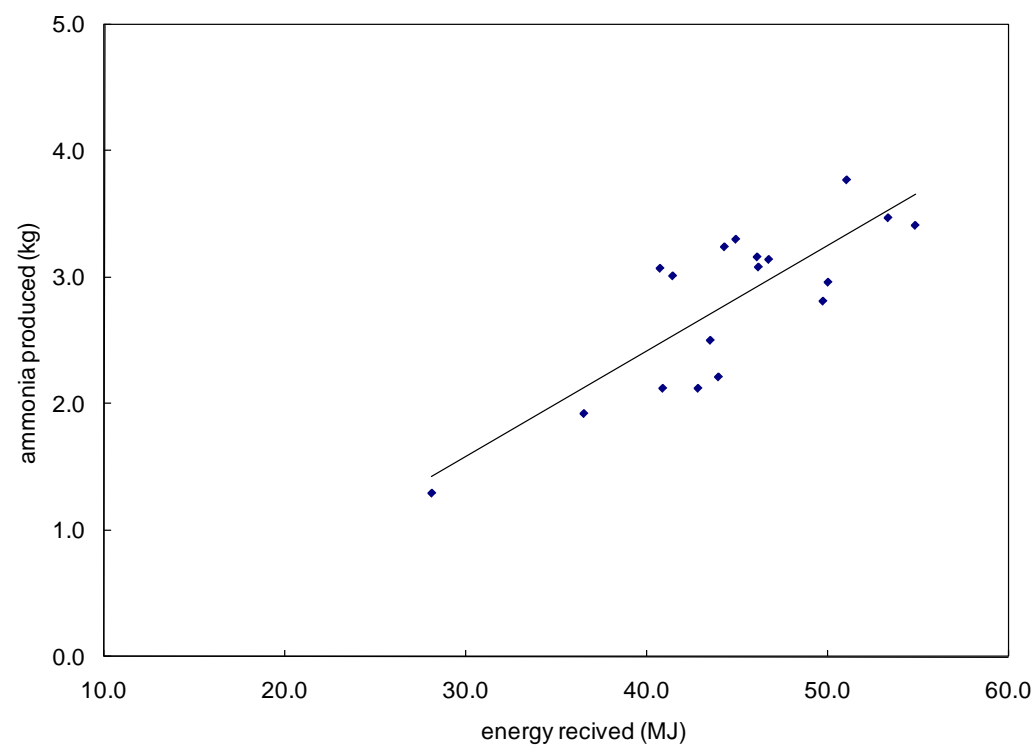

Fig. 5. Ammonia produced during the generation stage against the energy received. 
In Fig. 5 it can be seen that the amount of ammonia produced (measured after the sunshine hours in the level tube placed in the condensate tank) increases considerably with the increase of the energy received by the CPC. The amount of ammonia produced varied from $1.3 \mathrm{~kg}$ at an energy received of $28.2 \mathrm{MJ}$ to $3.8 \mathrm{~kg}$ at an energy received of $50 \mathrm{MJ}$. From this figure and from the explained in Fig. 4 that the amount of refrigerant produced (ammonia) is very dependent of the solar radiation received by the CPC.

In Fig. 6 it can be seen the solar coefficient of performance against the cooling capacity. It can be observed that the solar coefficient of performance increases considerably with and increases of the cooling capacity. The solar coefficient of performance varied from 0.06 at a cooling capacity of $1.7 \mathrm{MJ}$ to a 0.098 at a cooling capacity of $4 \mathrm{MJ}$.

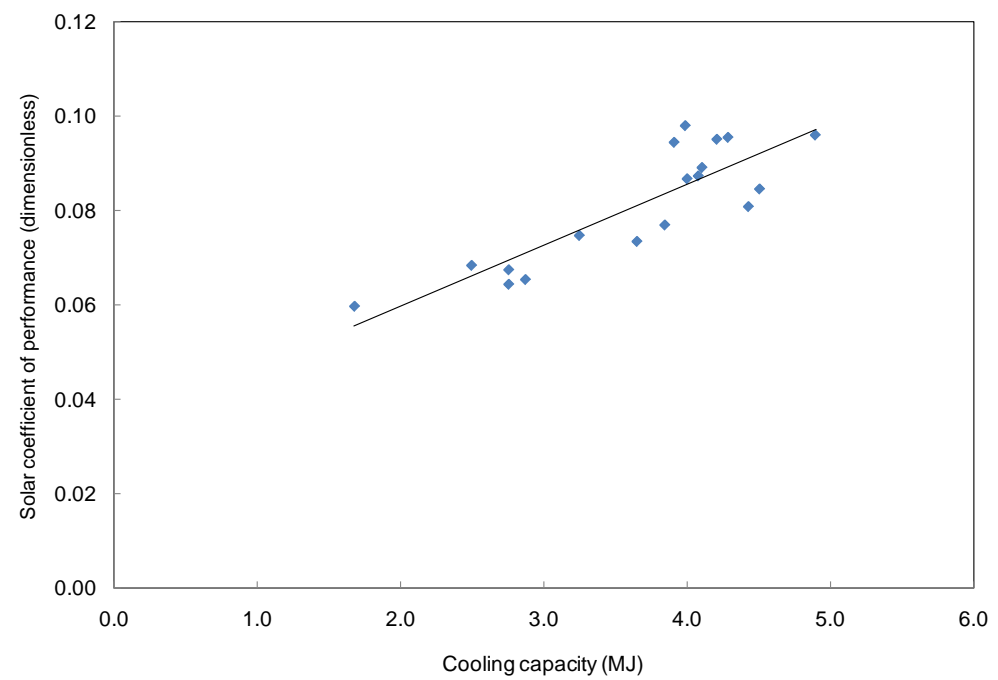

Fig. 6. Solar coefficient of performance against cooling capacity.

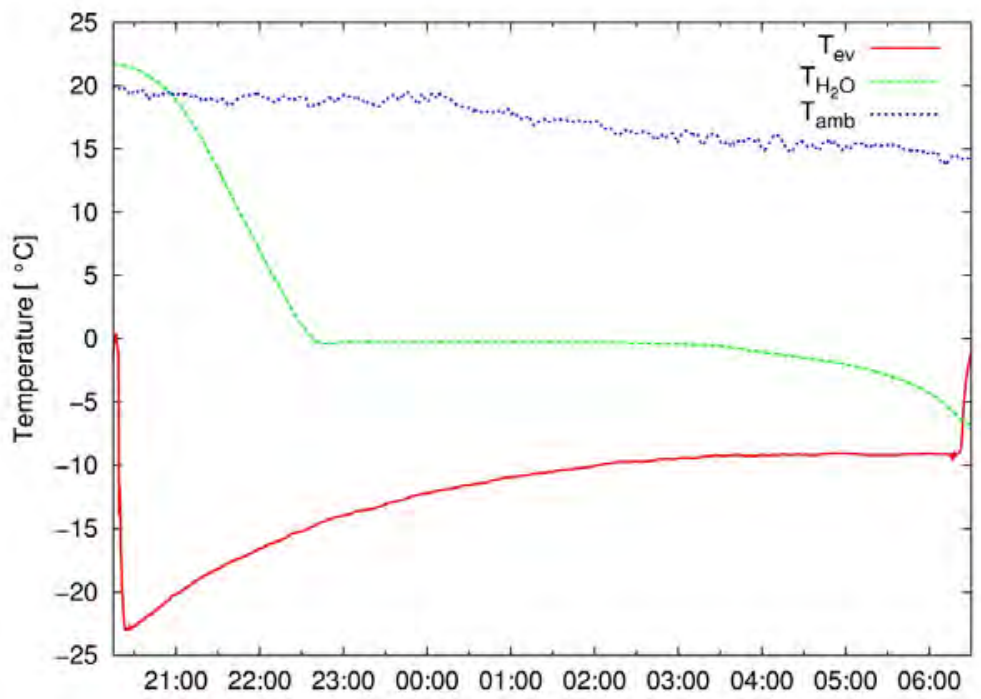

Fig. 7. Evaporator, water and ambient temperatures against time.

In Figure 7 it can be seen that the evaporator temperature was lower than $-11^{\circ} \mathrm{C}$ for a period 
higher than 8 hours. Also it can be seen how the water temperature decreases from the ambient temperature to $0^{\circ} \mathrm{C}$ and remains constant while the ice is been produced.

\section{Conclusions}

A solar intermittent refrigeration system for ice production has been evaluated with the ammonia/lithium nitrate/water mixtures at the Centro de Investigación en Energía of the UNAM. Evaporator temperatures as low as $-11^{\circ} \mathrm{C}$ were obtained for a period of time up to 8 hours. The solar coefficient of performance reached values up to 0.098 , which is $24 \%$ higher than the maximum obtained previously by Rivera [7] operating the system with the ammonia/lithium nitrate mixture.

\section{Acknowledgments}

The authors would like to thank to PAPIIT-UNAM project number IN110706-2 to sponsor the present research and to Dr. Victor Hugo Gómez Espinoza for his invaluable help.

\section{References}

[1] A. Erhard, K. Spindler, T. Hahne, Test and simulation of a solar powered solid sorption cooling machine, Int. J. Refrigeration 21(2), 1998, pp. 133-141.

[2] R. Z. Wang, Y. X. Xu, J. Y. Wu, M. Li, H. B. Shou, Research on a combined adsorption heating and cooling system, Applied Thermal Engineering 22, 2002, pp. 603-617.

[3] M. Li, R. Z. Wang, Y. X. Xu, J. Y. Wu, A.O. Dieng, Experimental study on dynamic performance analysis of a flat-plate solar solid-adsorption refrigeration for ice maker, Renewable Energy 27, 2002, pp. 211-221.

[4] C.Hildbrand, P Dind, M. Pons, F. Buchter, A new solar powered adsorption refrigerator with high performance. Solar Energy 77, 2004, pp. 311-318.

[5] N. M. Khattab, A novel solar-powered adsorption refrigeration module, Applied Thermal Engineering 24, 2004, pp. 2747-2760.

[6] M. Li, C. J. Sun, R. Z Wang, W. D Cai, Development of no valve solar ice maker, Applied Thermal Engineering 2004;24:865-872.

[7] W. Rivera, G. Moreno-Quintanar, C. O Rivera, R. Best, F. Martínez, Evaluation of a solar intermittent refrigeration system for ice production operating with ammonia/lithium nitrate, Solar Energy 85(1), 2011, pp. 38-45.

[8] S. Libotean, D. Salavera, M. Valles, J. Esteve, A. Coronas, Vapor-liquid equilibrium of ammonia+lithium nitrate+water and ammonia+lithium nitrate solution from (293.15 to 353.15) K, Journal Chemical and Engineering Data 52, 2007, pp. 1050-1055.

[9] S. Libotean, D. Salavera, M. Valles, J. Esteve, A. Coronas, Densities, viscosities, and heat capacities of ammonia + lithium nitrate and ammonia + lithium nitrate + water solutions between (293.15 to 353.15) K, Journal Chemical and Engineering Data 53, 2008, pp. 2383-2393. 